\title{
Auto-personalization: Theory, practice and cross-platform implementation
}

Vanderheiden, Gregg C., Treviranus, Jutta, Usero, Jose A. Martinez, Bekiaris, Evangelos, Gemou, Maria and Chourasia, Amrish O.

\section{Suggested citation:}

Vanderheiden, Gregg C., Treviranus, Jutta, Usero, Jose A. Martinez, Bekiaris, Evangelos, Gemou, Maria and Chourasia, Amrish O. (2012) Auto-personalization: Theory, practice and cross-platform implementation. In: Proceedings of the Human Factors and Ergonomics Society 56th Annual Meeting. Available at http://openresearch.ocadu.ca/id/eprint/1352/

Open Research is a publicly accessible, curated repository for the preservation and dissemination of scholarly and creative output of the OCAD University community. Material in Open Research is open access and made available via the consent of the author and/or rights holder on a non-exclusive basis.

The OCAD University Library is committed to accessibility as outlined in the Ontario Human Rights Code and the Accessibility for Ontarians with Disabilities Act (AODA) and is working to improve accessibility of the Open Research Repository collection. If you require an accessible version of a repository item contact us at repository@ocadu.ca. 


\title{
Auto-Personalization: Theory, Practice and Cross-Platform Implementation
}

\author{
Gregg C. Vanderheiden ${ }^{\text {a }}$, Jutta Treviranus ${ }^{\text {b }}$, Jose A. Martinez Usero ${ }^{c}$, Evangelos Bekiaris ${ }^{d}$, Maria Gemou \\ ${ }^{\mathrm{d}}$ and Amrish O. Chourasia ${ }^{\mathrm{a}}$ \\ ${ }^{a}$ Trace Research and Development Center, University of Wisconsin-Madison, Madison WI, USA \\ ${ }^{b}$ Inclusive Design Research Center, OCAD University, Toronto ON, Canada \\ ${ }^{c}$ Technosite, Madrid, Spain \\ ${ }^{d}$ Center for Research and Technology Hellas, Thessaloniki, Greece
}

\begin{abstract}
In an increasing digital society, access to information and communication technologies (ICT) is no longer just helpful but has become a necessity. However, the human interfaces appearing on these ICT (and increasingly, even common household products) are beyond of the abilities of many people with disability, digital literacy, or aging related limitations. Access to these ICT is essential to these individuals yet it is not possible to create an interface that is usable by all. This paper introduces a new approach to autopersonalization that is based on the development of the Global Public Inclusive Infrastructure (GPII). The GPII is a new international collaborative effort between users, developers and industry to build a sustainable infrastructure to make access to all digital technologies technically and economically possible, including access by users who are unable to use or understand today's technologies. Based on a one-sizefits-one approach, the GPII uses auto-adapting mainstream interfaces, and ubiquitous access to assistive technologies when mainstream interfaces cannot adapt enough, to provide each user with the interface they need. The GPII has three main components: a mechanism to allow individuals to easily discover which interface variations they need and then store it in a secure way on a token or in the cloud; a mechanism to allow them to use these stored needs and preferences to automatically adapt the interfaces on the digital technologies they encounter, anywhere and anytime; and a resource for developers (mainstream and assistive technology) providing the information and tools required to develop, disseminate, and support new access solutions more simply, more quickly, and at lower cost.
\end{abstract}

\section{INTRODUCTION}

The incidence of disability is rapidly increasing in the western world as its population ages. In the United States $52 \%$ of the population aged 65 and older and $21 \%$ of the population aged 15 and older experience a disability (US Census Bureau 2005). Up to $15 \%$ of the European Union population experiences a disability (European Commission Communications Committee Working Report 2004). These disabilities include visual, hearing, speech, cognitive or motor impairment disabilities. As the population and the proportion of those aged 65 and older increases the number of individuals with disabilities is bound to increase.

Individuals with or acquiring disabilities or functional limitations face the risk of not being able to use the interfaces on the information and communication technologies (ICT) that are rapidly moving into all aspects of life. Access to the Internet is becoming required for education, employment, commerce, civics, health and safety and yet many individuals with disabilities cannot understand and use the interfaces on web applications. The current accessibility technologies (AT) are expensive, available to only a few and will not work with many of the new technologies. With the rise in the population and number of individuals with disabilities, the problem will be further aggravated.

Development of accessible interfaces presents various problems for the users, developers and the ICT industry.
Traditionally AT development has taken a "user group" approach rather than a "user" approach. The user profile has been a profile that reflects a class of user or a representative persona (the user who is blind, the typical housewife) (Cooper, 2004). This presents a problem for individuals who do not fit into these profiles or whose unique needs are not expressed in the profile.

Developers report difficulties in not only designing for accessibility, but also in using the test tools and finding technology work-arounds. Testing and finding work-arounds are also the most time consuming aspects of accessibility, while design itself is not (Trewin, Cragun, Swart, Brezin, \& Richards, 2010). Some challenges faced by the ICT industry include limited market penetration, high cost of development, marketing, distributing and supporting assistive technologies and the high cost for development of new approaches.

Moreover, most of the AT development companies tend to be small companies (5-15 individuals) making it further difficult for them to keep up with developments in ICTs.

However, the very advancements in ICT that present the barriers also present an opportunity to make ICT more accessible to individuals with disabilities. Cloud computing is a model for enabling ubiquitous, convenient, on-demand network access to a shared pool of configurable computing resources (e.g., networks, servers, storage, applications, and services) that can be rapidly provisioned and released with minimal management effort or service provider interaction (National Institute of Standards and Technology, 2011). 
Cloud-based Auto-Personalization taps this unprecedented ability to pool resources and match demand with supply enabled by the Cloud. It allows for ease of setup and use that can result form the use of personal preference profiles to allow delivery of instant personalization of interfaces to every individual where they need it, when they need it and in a way that matches their unique requirements; automatically so that they do not need to negotiate, explain, qualify or justify. For most of us this can just make things easier to use. But for many this would allow them to have interfaces that were usable to them for the first time.

This paper describes a new approach to auto-personalization that is based on the development of a Global Public Inclusive Infrastructure (GPII). The GPII is a new international collaborative effort to build a sustainable infrastructure based on cloud, web and platform technologies with a goal of making access to all digital technologies more technically and economically possible, and to allow access even in countries with no assistive technology infrastructure.

\section{PRACTICAL INNOVATION}

The GPII initiative is a synthesis of ideas and efforts from many people and programs in the US, Canada, Europe and other countries. It is a concept that grew out of the Raising the Floor initiative (www.raisingthefloor.org), which is now coordinating the international efforts on GPII. Raising the Floor, a non-profit association based in Switzerland, is coordinating the coalition of academics, ICT industry (IBM, Microsoft, etc.), assistive technology companies, practitioners and consumers (individual and in all of the above) that is building the GPII. There are currently about 30 organizations and over 100 programmers, designers, researchers, practitioners working on the GPII and its components -- and the participation is continuously growing.

The GPII concept is based on three pillar functions (Vanderheiden and Treviranus 2011):

1. Providing a way for people to easily learn about, and determine what solutions/features would help them and then to store that information in a common, portable, private, and secure manner.

2. Providing a way to use their stored preferences (and permissions) to invoke and configure the accessibility and usability features, assistive technologies, and/or services that they need - anywhere, anytime, on any device they need to use.

3. Providing the tools and infrastructure needed to allow diverse developers and vendors to create new solutions for these different users and platforms and to easily and cost effectively move them to market and to users internationally.

The components that make up each of these is shown in figure 1 along with the components being advanced by the Cloud4all. Cloud4all is a European Commission funded program to develop advance and test key aspects of the GPII. Cloud4all consists of 30 members and collaborators in Europe, Canada, and the US.

\section{Will something help me? What?}

\section{Getting access automatically, anywhere, on any device}
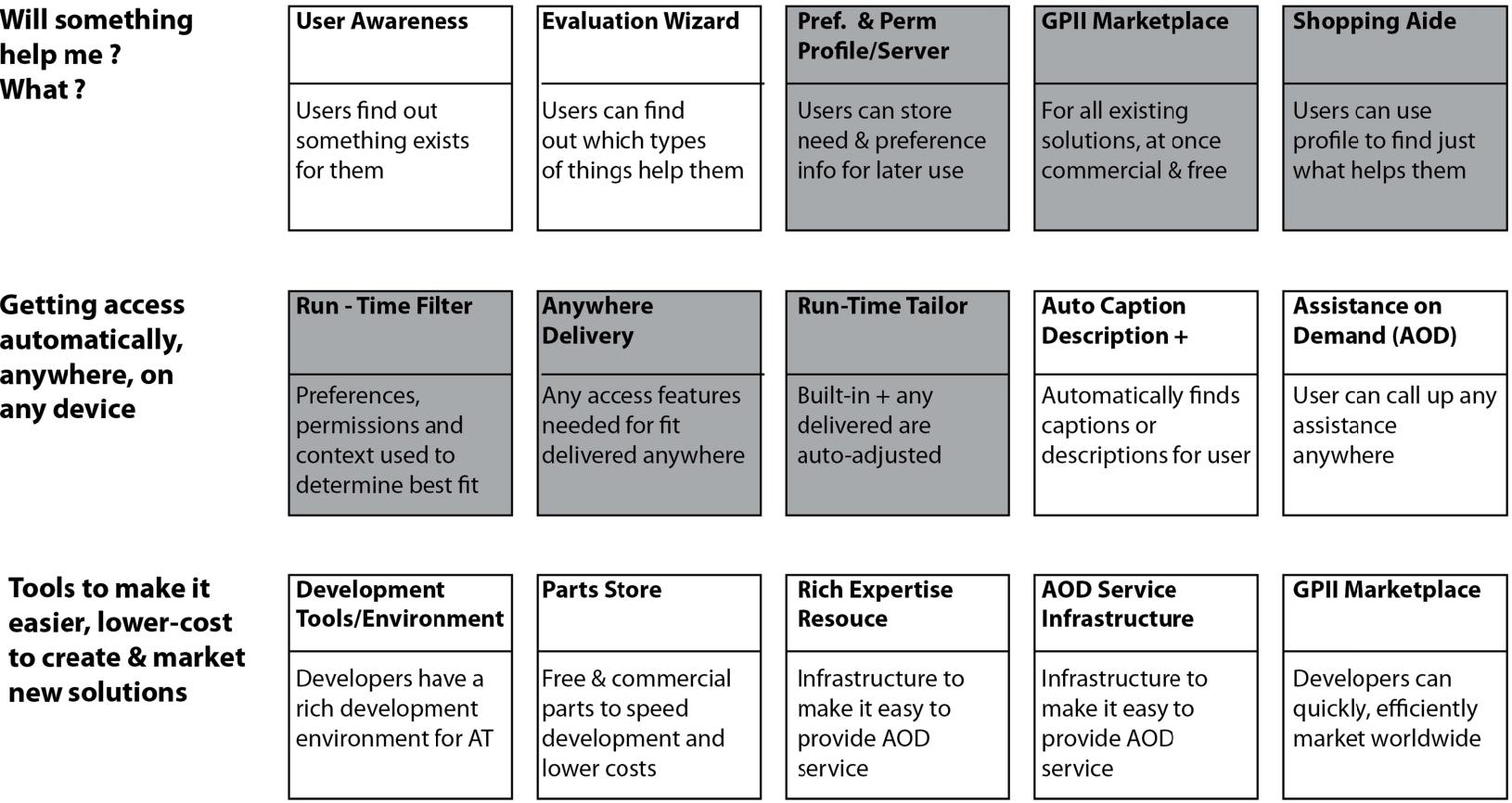

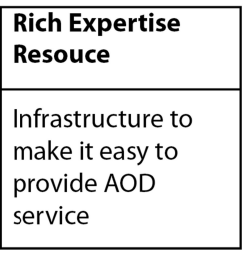

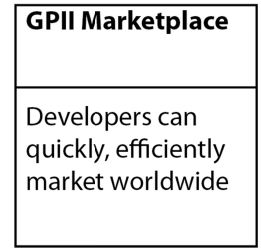




\section{Personalization Components Of GPII/Cloud4all}

The core components of the basic GPII/Cloud4all personalization structure are shown in figure 2 .

The core components to the personalization structure are:

1. Personal Needs and Preference Capture Mechanism(s) (different types)

2. Preference Storage Mechanism(s) (cloud, USB, other)

3. Mechanism(s) for person to ID themselves to the server (but not necessarily to the device)

4. Matchmaker that determines the settings for the ICT (based on settings and other factors)

5. Settings-Handler that configures ICT (or content) to fit the user's needs (often part of the ICT itself)

6. The adapted ICT (including built-in features and AT)

The procedure followed is composed of the following steps:

1. User preferences are gathered;

2. Then stored for later use;

3. The person ID's themselves to the server (but not necessarily to the device);

4. The preferences go to a Matchmaker that determines the settings for the ICT based on preferences, ;

5. The Settings-Handler configures ICT to fit the user's needs as instructed by Matchmaker;

6. The user interface on the ICT changes to match the users needs and preferences based on what is possible and best on this ICT in the environment/use.

*(Alternate step $5 \& 6$ ): The tailor alters the content on the web or causes alternate form of content to be served to the ICT.

\section{FINDINGS}

GPII will use cloud technologies and user preferences to augment and invoke built-in access technologies in mainstream ICT (Figures $3 \& 4$ ). The basic architecture of the GPII has been developed and a first implementation of the GPII has been built and is undergoing a 3-year test. More than 18 implementations that are compatible with the GPII have been developed. These include computer platforms and programs such as Linux, Microsoft Windows, Microsoft Internet Explorer, Mozilla Firefox, Android Mobile operating system, web apps, assistive technologies, phones (smart, simple and soft), kiosks, Microsoft Surface and digital TV. The first set of 8 implementations was demonstrated at the 2012 World Summit of the Information Society meeting at the UN in Geneva Switzerland.

Table 1 lists the currently available accessibility features are built-in in some of the popular ICT that can be auto-set to a user's personal needs and preferences using the GPII. Those marked with an asterisk will be supporting the preliminary GPII implementation in 2012, at least on a prototype level. One assistive technology vendor (Texthelp Systems Inc.) will support the GPII directly in a shipping product (Read\&Write Gold).

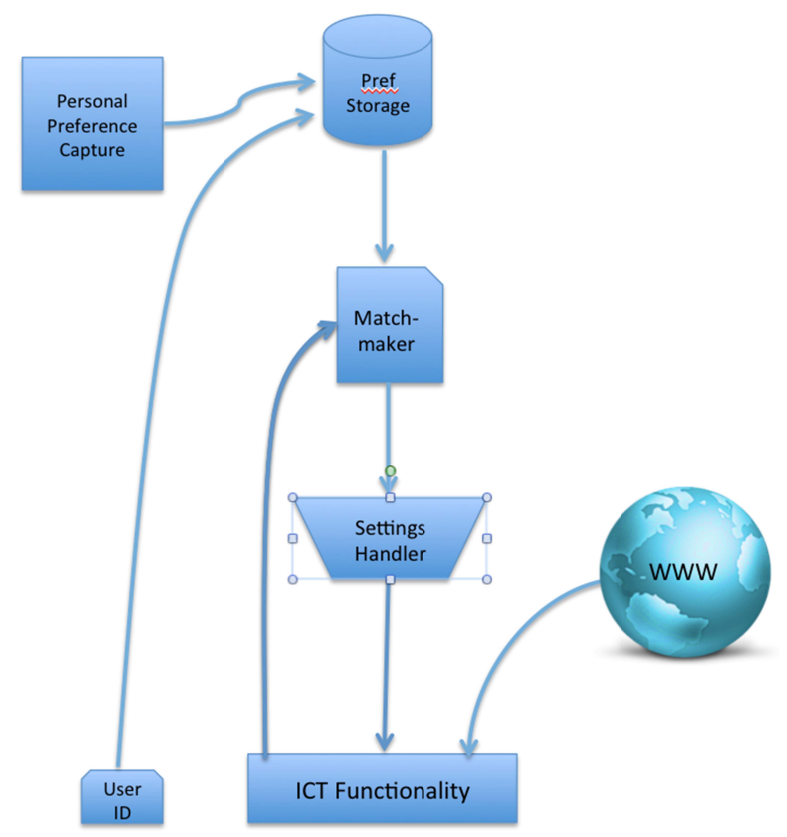

Figure 2. Core Components of the GPII personalization structure. Elements above are function, not necessarily different software modules. Several functions may be provided by a single software module depending on implementation.

\section{Before GPII/Cloud4All}

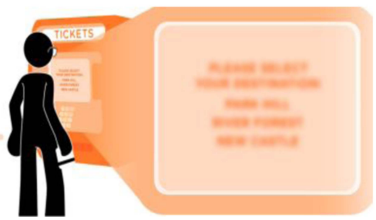

Figure 3: Solutions and services in daily environments may not be accessible to users who encounter them. One example is kiosks and fare machines

\section{After GPII/Cloud4AII}
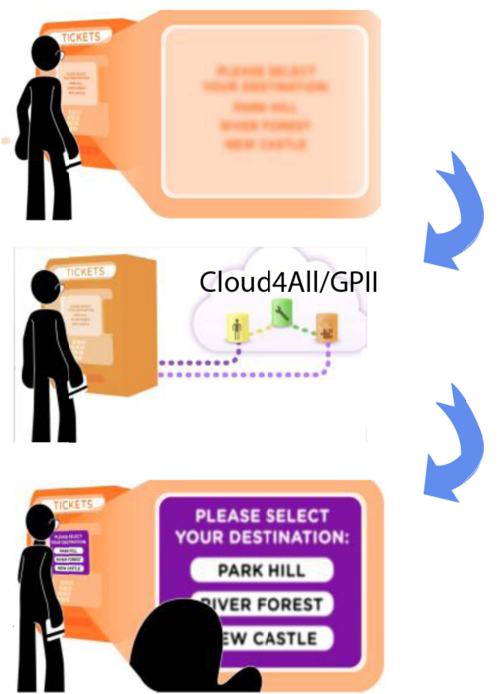

Figure 4: With GPII/Cloud4all the interface will adapt to the user automatically based on user needs profile on a card or in the cloud. 
Table 1: Built-in accessibility features of popular ICT platforms that would be auto-settable by the GPII. Additional assistive technologies from third party developers can be auto- launched, set, and sometimes downloaded and installed by GPII.

\begin{tabular}{|c|c|c|c|c|c|c|c|}
\hline & & $\begin{array}{c}\text { *Windows } \\
7.0^{\mathrm{a}}\end{array}$ & $\begin{array}{l}* \text { Linux } \\
\text { Gnome }^{\mathrm{b}}\end{array}$ & OS X (Lion) $)^{\mathrm{c}}$ & $\operatorname{iOS} 5.0^{\mathrm{c}}$ & *Android ${ }^{\mathrm{d}} 4.0$ & *Kiosks \\
\hline \multicolumn{8}{|l|}{ Blindness } \\
\hline & Screen reader/Self-Voice & 1 & $\mathrm{X}$ & $\mathrm{X}$ & $\mathrm{X}$ & 1 & $\mathrm{X}$ \\
\hline & Speech recognition & $\mathrm{X}$ & $\mathrm{X}$ & $\mathrm{X}$ & $\mathrm{X}$ & $\mathrm{X}$ & $\mathrm{X}$ \\
\hline & Braille output & $\mathrm{X}$ & $\mathrm{X}$ & $\mathrm{X}$ & $\mathrm{X}$ & - & - \\
\hline \multicolumn{8}{|l|}{ Low Vision } \\
\hline & Screen reader/Self-Voice & 1 & $\mathrm{X}$ & $\mathrm{X}$ & $\mathrm{X}$ & / & $\mathrm{X}$ \\
\hline & Screen magnification & $\mathrm{X}$ & $\mathrm{X}$ & $\mathrm{X}$ & $\mathrm{X}$ & - & $\mathrm{X}$ \\
\hline & $\begin{array}{l}\text { Display customization (Font } \\
\text { size, contrast, cursor size etc) }\end{array}$ & $\mathrm{X}$ & $\mathrm{X}$ & $\mathrm{X}$ & $\mathrm{X}$ & $\mathrm{X}$ & $\mathrm{X}$ \\
\hline & Speech recognition & $\mathrm{X}$ & $\mathrm{X}$ & $\mathrm{X}$ & $\mathrm{X}$ & $\mathrm{X}$ & $\mathrm{X}$ \\
\hline \multirow{4}{*}{$\begin{array}{l}\text { Deaf and } \\
\text { Hard of } \\
\text { Hearing }\end{array}$} & & & & & & & \\
\hline & Visual notification of sounds & $\mathrm{X}$ & - & $\mathrm{X}$ & - & - & $\mathrm{X}$ \\
\hline & Closed captions support & $\mathrm{X}$ & - & $\mathrm{X}$ & $\mathrm{X}$ & - & $\mathrm{X}$ \\
\hline & Mono audio & - & - & $\mathrm{X}$ & $\mathrm{X}$ & - & $\mathrm{X}$ \\
\hline \multirow{4}{*}{$\begin{array}{l}\text { Physical } \\
\text { Disabilities }\end{array}$} & & & & & & & \\
\hline & $\begin{array}{l}\text { Adjustable input devices } \\
\text { (Mouse keys, Sticky keys, On } \\
\text { screen keyboard) }\end{array}$ & $\mathrm{X}$ & $\mathrm{X}$ & $\mathrm{X}$ & $\mathrm{X}$ & - & $\mathrm{X}$ \\
\hline & Word Completion & $\mathrm{X}$ & $\mathrm{X}$ & $\mathrm{X}$ & $\mathrm{X}$ & $\mathrm{X}$ & - \\
\hline & Speech recognition & $\mathrm{X}$ & $\mathrm{X}$ & $\mathrm{X}$ & $\mathrm{X}$ & $\mathrm{X}$ & $\mathrm{X}$ \\
\hline \multirow{6}{*}{$\begin{array}{l}\text { Cognitive, } \\
\text { Language \& } \\
\text { Learning } \\
\text { Disabilities, } \\
\text { and Low } \\
\text { Literacy }\end{array}$} & & & & & & & \\
\hline & Screen reader/Self-Voice & 1 & $\mathrm{X}$ & $\mathrm{X}$ & $\mathrm{X}$ & 1 & $\mathrm{X}$ \\
\hline & Display customization & $\mathrm{X}$ & $\mathrm{X}$ & $\mathrm{X}$ & $\mathrm{X}$ & $\mathrm{X}$ & $\mathrm{X}$ \\
\hline & Adjustable input devices & $\mathrm{X}$ & $\mathrm{X}$ & $\mathrm{X}$ & $\mathrm{X}$ & - & $\mathrm{X}$ \\
\hline & Dictionary support & (Word) & $\mathrm{X}$ & $\mathrm{X}$ & $\mathrm{X}$ & - & - \\
\hline & Word completion & - & - & $\mathrm{X}$ & $\mathrm{X}$ & - & - \\
\hline
\end{tabular}

${ }^{\mathrm{a}}$ Microsoft (2012); ${ }^{\mathrm{b}}$ Gnome Project (2012); ${ }^{\mathrm{c}}$ Apple Inc.(2012); ${ }^{\mathrm{d}}$ Google Inc. (2012)

* indicates support for the GPII at prototype level in 2012.

\section{DISCUSSION}

The GPII provides the opportunity for a paradigm shift in both accessibility and usability. It can allow developers to build more flexibility and options into their products and have some confidence that users will actually find and use them.

Previous research (Baker and Moon, 2008) has shown that today, even when companies provide built-in access features they are rarely known and used.

The GPII also expands the potential for AT as a service and for virtual AT that can appear on any device the user approaches that is compatible with it. It also greatly simplifies that invocation and use of network (cloud) based assistive technologies.

The concept of auto-personalization is not new and is common on platforms and local systems. The US Navy even has assistive technologies that automatically appear on workstations when a user signs on. All attempts to create a generic, cross platform approach to this to date have not taken root. Proprietary interests may be one reason.

Because this approach is not based on providing a convenience to users in the form of auto-preference application, but rather targets individuals who need such a system in order to provide access, it has moved further than previous efforts. The technologies are also in place now that were not present earlier. Finally, it is perhaps the only affordable way to provide access across all the different users, technology platforms, languages and geographies.

The GPII is still in its early stages of conceptualization and development phases. Because the GPII is a software and service enhancement to the broadband infrastructure it is quite flexible and open to expansion and elaboration. The consortium working on it seeks participation and inputs from users, organizations, academics, practitioners, and developers of assistive and mainstream information and communication technologies. If it can substantially improve accessibility over the next ten years, it will open up access to, and improve the use of, ICT products and services in general (whether eCommerce, eGovernment, eHealth, eCulture, or Internet banking) and make opportunities available for the elderly and for people with disabilities (i.e. to make online job applications, use job-matching platforms or eLearning applications). Whereas, the lack of accessibility or even maintenance of the status quo would further compound social exclusion, its improvement can contribute to greater social inclusion (better access to health and public services, improved employability and productivity, increased embeddedness for individuals in social relations and networks, and more) (Vanderheiden and Treviranus 2011). 


\section{ACKNOWLEDGMENTS}

Initial funding for the development of the GPII concept and components has come from a broad range of sources including the US National Institute On Disability and Rehabilitation Research (NIDRR) grant number H133E080022 (RERC on Universal Interface \& Information Technology Access), the William and Flora Hewlett Foundation, the Canadian government, the European Commission, the Adobe foundation and the funders of the other participants in Raising the Floor. Opinions expressed herein are those of the authors and do not necessarily reflect those of the funding agencies. For more information see www.raisingthefloor.org .

\section{REFERENCES}

Apple Inc. (2012). Accessibility, from http://www.apple.com/accessibility/

Baker, P., \& Moon, N. (2008). Wireless technologies and accessibility for people with disabilities: findings from a policy research instrument. Assistive technology: the official journal of RESNA, 20(3), 149.

US Census Bureau. (2005). Survey of Income and Program Participation.

Cooper, A. (2004). The Inmates Are Running the Asylum: Why High Tech Products Drive Us Crazy and How to Restore the Sanity (2nd Edition).

Gnome Project. (2012). GNOME Accessibility Gide, from http://library.gnome.org/users/gnome-accessguide/stable/

Google Inc. (2012). Android 4.0 Accessibility Features, from http://developer.android.com/sdk/android-4.0highlights.html - UserFeatures

KDE. (2012). KDE Accessibility, from http://userbase.kde.org/Applications/Accessibility

Microsoft Corporation. (2012). Windows Accessibility, from $\mathrm{http}: / /$ windows.microsoft.com/enUS/windows/help/accessibility

National Institute of Standards and Technology. (2011). NIST Definition of Cloud Computing

Raising the Floor. (2012). from http://www.raisingthefloor.org European Commission Society Directorate General of Information (2004). Working Document - Report from the inclusive communications (INCOM) subgroup (COCOM04-08).

Trewin, S., Cragun, B., Swart, C., Brezin, J., \& Richards, J. (2010). Accessibility challenges and tool features: an $I B M W e b$ developer perspective. Paper presented at the Proceedings of the 2010 International Cross Disciplinary Conference on Web Accessibility (W4A).

Vanderheiden, G. T., Jutta. (2011). Cloud-based AutoPersonalization for More Universal Accessibility. Paper presented at the 6th Universal Access in Human-Computer Interaction Conference. Design for All and eInclusion, Orlando, FL, USA. 